\title{
Glycosylated hemoglobin as an efficacious tool for early prediction of gestational diabetes mellitus
}

\author{
Sneha D. Shendre ${ }^{1}$, Vijayalakshmi Palanisamy ${ }^{1 *}$, Swanand S. Rewatkar ${ }^{2}$
}

\begin{abstract}
${ }^{1}$ Department of Obstetrics and Gynaecology, ${ }^{2}$ Department of Paediatrics, Shri Sathya Sai Medical College and Research Institute, Ammapettai, Tamil Nadu, India
\end{abstract}

Received: 29 January 2021

Accepted: 04 March 2021

\author{
*Correspondence: \\ Dr. Vijayalakshmi Palanisamy, \\ E-mail: vijayalakshmi01434@gmail.com
}

Copyright: (c) the author(s), publisher and licensee Medip Academy. This is an open-access article distributed under the terms of the Creative Commons Attribution Non-Commercial License, which permits unrestricted non-commercial use, distribution, and reproduction in any medium, provided the original work is properly cited.

\begin{abstract}
The incidence and prevalence of GDM is on the rise worldwide and, more so in developing countries including India. GDM is associated with maternal, fetal and neonatal morbidities. Current guidelines recommend GDM screening only at 24-28 weeks of gestation. Diagnosis of GDM in later half of pregnancy leads to fetal and maternal morbidities in spite of good glycemic control. This necessitates the use of a simpler, convenient, accurate, and reliable test, which can predict GDM in early gestation. Our article reviews the scope of using HbA1c for GDM and its efficacy in screening GDM.
\end{abstract}

Keywords: Gestational diabetes mellitus, HbA1c, OGTT, Screening test, First trimester screening

\section{INTRODUCTION}

Gestational Diabetes Mellitus is "carbohydrate intolerance in severity of varying degrees that is first recognized during pregnancy". ${ }^{1}$ It is well known that GDM is associated with fetal and maternal complications. ${ }^{2}$ With its rising incidence and prevalence worldwide, GDM is having a huge impact especially on developing countries including India. India ranks second in diabetic population with a high figure as high as 62.4 million, which is expected to touch 100 million by the year $2030 .^{3}$ The prevalence varies in the urban and rural settings in our country with $4.6-14 \%$ being the prevalence range in urban areas and $1.7-13.2 \%$ prevalence in rural areas. ${ }^{4}$ Furthermore, there is geographic variation in the prevalence rates of GDM in India which could be attributed to factors like dietary habits, age, maternal obesity, socioeconomic status, etc. We have a prevalence variation ranging from $3.8 \%$ in Kashmir and going as high as $17.9 \%$ in Tamil Nadu. ${ }^{4}$ Changed dietary patterns and sedentary lifestyle have led to increased incidence of diabetes mellitus (DM) and a parallel rise in GDM as well. ${ }^{5}$
GDM leads to fetal complications like congenital anomalies, macrosomia, hypoglycemia, shoulder dystocia, and stillbirth also. ${ }^{6,7}$ The children born to GDM mothers also have high chances of developing obesity and DM in later life. ${ }^{8}$ Maternal complications include increased numbers of $\mathrm{C}$-sections, perineal injuries during birth of a macrosomic baby, pregnancy induced hypertension $(\mathrm{PIH})$ and future development of DM or some form of glucose intolerance even after delivery. $4,7,9,10$

Despite these severe morbidities involving both the mother and baby in intrauterine and extrauterine life, it is seen that GDM is mostly asymptomatic going unnoticed till routine screening is done. ${ }^{1}$ According to the current guidelines, this routine screening is done at 24-28 weeks through 75g OGTT (oral glucose tolerance test) and diagnosing GDM by IADPSG (International Association of Diabetes and Pregnancy Study Groups) criteria. ${ }^{1}$ But, this test is cumbersome requiring venipuncture in the antenatal woman three times for blood samples with a prerequisite of fasting for a minimum of 8 hours. Further, lack of any specific standard guideline and numerous criteria by WHO, American Diabetes Association (ADA), etc. adds to the confusion. Screening and diagnosing GDM in later 
half of pregnancy, delays the initiation of management and leads to above morbidities in spite of good glycemic control after diagnosis. ${ }^{11}$

It is well known that GDM if well controlled, can prevent the perinatal complications. ${ }^{12}$ Hence, an universally acceptable, reliable and sensitive test, which could facilitate early detection of GDM is required in view of high prevalence and related morbidities and mortalities which are preventable. Glycosylated hemoglobin is one such test that can be used as a tool for early detection of GDM. It has the convenience of being simple, needing a single prick, not needing fasting state and requiring very less amount of blood sample. HbA1c if used effectively as a tool for GDM detection in first trimester, may prevent maternal, fetal and neonatal morbidities, and also distinguish pre-GDM from GDM, thus changing line and intensity of management. ${ }^{11}$

\section{CLASSIFICATON OF DIABETES MELLITUS}

\section{Etiological classification}

Diabetes mellitus may be classified as Type 1, type 2, other types and GDM based on etiology. Type 1 is caused by destruction of the beta-cells of pancreas leading to insulin deficiency. This can be immune mediated or idiopathic. Type $2 \mathrm{DM}$ is a result of insulin resistance at the tissue level. Other types of DM are caused due to genetic mutations, genetic defects, pancreatitis, cystic fibrosis, endocrinopathies, chemical induced or infections. Gestational Diabetes Mellitus is glucose intolerance of any severity first detected during pregnancy.

\section{Diabetes in pregnancy}

A classification system has been proposed for diabetes in pregnancy. ${ }^{13}$ This is because the presence of preexisting hyperglycemia in pregnancy may produce vascular changes, thus exaggerating adverse pregnancy outcomes.

Under this classification, the types of diabetes in pregnancy are - Gestational diabetes which is first detected during pregnancy and is not overt diabetes (not included in type 1 or type $2 \mathrm{DM}$ ). The next class is type 1 diabetes in pregnancy, which is due to pancreatic beta cell destruction. It is further classified as, with or without vascular involvement. Type 2 diabetes in pregnancy is due to tissue insulin resistance and is further classified as with or without vascular involvement. Other types of diabetes in pregnancy have genetic, inflammatory, chemical or drug induced etiology. The prior vascular involvement in pregnancy signifies increased chances of adverse outcomes.

The overt diabetes or pre-gestational diabetes is diagnosed based on fasting blood glucose, 2-hr post 75-gm anhydrous glucose during OGTT, HbA1c and RBS. ${ }^{14,15}$ Cut-off values of the above parameters are as follows - Fasting blood glucose $\geq 126 \mathrm{mg} / \mathrm{dl}$ or $7 \mathrm{mmol} / \mathrm{L}, 2$-hr reading of 75-gm OGTT $\geq 200 \mathrm{mg} / \mathrm{dl}, \mathrm{HbA} 1 \mathrm{c} \geq 6.5 \%$ and Random blood glucose of $\geq 200 \mathrm{mg} / \mathrm{dl}$ or $11.1 \mathrm{mmol} / \mathrm{L}$ with symptoms of hyperglycemia.

\section{Physiology of carbohydrate metabolism in pregnancy}

The carbohydrate metabolism undergoes numerous changes during pregnancy which ensures appropriate nutrient allocation to the fetus and the mother. ${ }^{16}$ The placental hormones contribute in these changes, which is proven by the fact that GDM resolves after termination of pregnancy.

Physiological hemodilution in early gestation leads to drop in maternal fasting levels of blood glucose. These levels are comparatively constant in second trimester with a further fall during the third trimester. ${ }^{17}$ Increased consumption of glucose by fetoplacental unit and decreased insulin sensitivity cause this fall in fasting blood sugar levels in the third trimester. ${ }^{17}$ Fasting blood glucose levels comparison in non-pregnant and pregnant states, show lower values in pregnancy. Drop in the fasting levels lead to an increased post-prandial blood sugar levels in pregnancy. ${ }^{18}$ Increased hepatic gluconeogenesis and high levels of free fatty acids are also seen in pregnancy. The raised PPBS is a result of -

Insulin resistance which occurs due to placental hormones like human placental lactogen, and placental inflammatory mediators along with other hormones like progesterone, cortisol and prolactin. ${ }^{19}$

Pancreatic beta-cell changes occur due to insulin resistance causing increase in insulin secretion. An increase in the number and size of beta cells is seen.

Hepatic gluconeogenesis is increased as a result of insulin resistance to achieve normal levels of blood glucose.

\section{PATHOPHYSIOLOGY OF GESTATIONAL DIABETES MELLITUS}

The etiology of Gestational Diabetes is attributed to following factors:

- Insulin resistance at tissue level. ${ }^{20}$

- Pancreatic beta-cell dysfunction due to increased load on these cells in order to produce excess insulin to combat with the pregnancy induced insulin resistance. $^{20}$

- Adiponectin and leptin cause neurohormonal regulation.

- Hepatic gluconeogenesis is increased in GDM.

- The mitochondrial number and function is reduced in cardiac and skeletal muscles. ${ }^{21}$

- Gut microbiome disturbances also contribute in metabolic disorders. ${ }^{20}$

- Placental hormones and cytokines.

- Oxidative stress. 
Presence of these factors before pregnancy and their progress may lead to type $2 \mathrm{DM}$ after delivery. ${ }^{22}$

\section{RISK FACTORS FOR GESTATIONAL DIABETES MELLITUS $^{23-25}$}

The risk factors for GDM are increased maternal age, obesity and high pre-pregnancy BMI, high order of parity, history of diabetes in a first degree relative, previous obstetric history of glucose intolerance, $\mathrm{PIH}$, preterm birth, miscarriages, stillbirth, birth of a macrosomic baby or fetal anomalies and history of polycystic ovarian syndrome.

\section{MATERNAL AND FETAL EFFECTS OF GESTATIONAL DIABETES MELLITUS}

\section{Effects on the mother ${ }^{26}$}

Diabetic complications such as nephropathy, retinopathy, neuropathy and ketoacidosis may be seen in GDM. Also, the GDM mothers are at high risk of developing preeclampsia and are more susceptible to infections.

\section{Effects on the fetus ${ }^{27}$}

Congenital anomalies, macrosomia, polyhydramnios, preterm bith, spontaneous abortions and unexplained fetal death are some of the effects on fetuses of GDM mothers.

\section{Effects on the neonates ${ }^{28}$}

The neonates born to GDM mothers are susceptible to development of respiratory distress syndrome, hypocalcemia, hypoglycemia, hyperbilirubinemia, cognitive defects, cardiomyopathy and increased risk of inheriting DM.

\section{SCREENING AND DIAGNOSIS OF GDM}

$50 \mathrm{gm}$ OGCT (Oral Glucose Challenge Test) is recommended for screening of GDM according to the guidelines by American Diabetic Association and the American Congress of Obstetricians and Gynaecologists. The cut-off value of the 1-hr blood glucose level post the 50 -gm glucose load is $140 \mathrm{mg} / \mathrm{dl}$ and levels $\geq 140 \mathrm{mg} / \mathrm{dl}$ are taken as positive. Antenatal women with positive OGCT are subjected to 3-hr 100-g OGTT.

\section{DIAGNOSIS}

Diagnosis of GDM is done by one-step or two-step approach.

The one-step approach is recommended by IADPSG and WHO. ${ }^{29}$

A 75 gram glucose load is given to fasting antenatal women at 24-28 weeks in this approach. IADPSG recommends testing the fasting, 1-hr and 2-hr blood glucose values with $\geq 92 \mathrm{mg} / \mathrm{dl}, \geq 180 \mathrm{mg} / \mathrm{dl}$ and $\geq 153$ $\mathrm{mg} / \mathrm{dl}$ as positive test results. If one or more of these values are above the given cut-offs, diagnosis of GDM is made. On the other hand, WHO recommends testing blood glucose value at fasting and 2 -hr post the glucose load. Fasting blood glucose $\geq 126 \mathrm{mg} / \mathrm{dl}$ or $2-\mathrm{hr} \geq 200 \mathrm{mg} / \mathrm{dl}$ is considered as diagnostic. ${ }^{15}$

Two-step approach is recommended by ACOG and is performed at gestational age of 24-28 weeks. ${ }^{15}$ First step involves giving of $50 \mathrm{-g}$ glucose solution with a 1-hr plasma glucose level cut-off of $135 \mathrm{mg} / \mathrm{dl} .{ }^{30}$ Those with 1 hr value $\geq 135 \mathrm{mg} / \mathrm{dl}$ are considered positive and subjected to second step involving 100-g OGTT. Blood glucose values of $\geq 95 \mathrm{mg} / \mathrm{dl}, \geq 180 \mathrm{mg} / \mathrm{dl}, \geq 155 \mathrm{mg} / \mathrm{dl}$ and $\geq 140$ $\mathrm{mg} / \mathrm{dl}$ are taken as positive for fasting, 1-hr, 2-hr and 3-hr, respectively. This guideline recommends that GDM can be diagnosed if $\geq 1$ value is positive.

Along with these standard tests for screening and diagnosis of GDM, many studies have evaluated glycosylated hemoglobin (HbA1c) as a screening tool for early detection of GDM. HbA1c is a hemoglobin with irreversibly glycated valine at the $\mathrm{N}$-terminal of beta-chain of hemoglobin through non-enzymatic glycation pathway. ${ }^{31}$ It indicates plasma glucose concentration over a period of 3 months and helps to differentiate pre-GDM and GDM. This test is convenient, inexpensive, involves withdrawal of blood sample only once and does not require the antenatal woman to be in a fasting state. Also, HbA1c shows minimal day-to-day variability as well as inter and intra-individual variability. The disadvantages of HbA1c are that it is unreliable in cases of hemoglobin traits, hemolytic anemias, blood transfusions and major blood loss. It is measured by high performance liquid chromatography (HPLC) technique. It is seen that HbA1c displays pregnancy-specific changes with resultant varying values in different trimesters of pregnancy. ${ }^{32}$

Study done by Agarwal et al shows that HbA1c at a cutoff value of $<5.5 \%$ has a specificity of $95.8 \%$, sensitivity of $82.1 \%$, positive and negative predictive value of $28.6 \%$ and $83.3 \%$, respectively. ${ }^{33}$ Through their study, they concluded that $\mathrm{HbA} 1 \mathrm{c}$ is capable of eliminating the need of OGTT in $25.1 \%$ women with a $27 \%$ false positive rate. They did not recommend HbA1c as a good tool for diagnosis of GDM.

Amreen et al got a sensitivity and specificity of $80 \%$ and $55.3 \%$, respectively and a positive and negative predictive value of $63.8 \%$ and $73.7 \%$, respectively after taking $\mathrm{HbA} 1 \mathrm{c}$ value of $5.5 \% .{ }^{13}$ They concluded that HbA1c is an effective tool to predict GDM.

Aldasouqui et al studied sensitivity of $\mathrm{HbA} 1 \mathrm{c}$ in predicting GDM at different cut-off values. ${ }^{34}$ They found that the sensitivity of $\mathrm{HbA} 1 \mathrm{c}$ was $100 \%, 98.4 \%$ and $62 \%$ at cut-off of $5 \%, 5.5 \%$ and $6.5 \%$, respectively. They also gave positive comments regarding use of $\mathrm{HbAlc}$ as an early predictor of GDM. 
Arbib et al used HbA1c value of $5.45 \%$ and got specificity of $69 \%$, sensitivity of $83.3 \%$, positive and negative predictive values of $53 \%$ and $90.8 \%$, respectively. ${ }^{35}$ The conclusion of their retrospective study was that $\mathrm{HbA} 1 \mathrm{c}$ has a role as biomarker of GDM in first trimester of pregnancy.

Duke et al got a specificity of $58 \%$, sensitivity of $54 \%$ with a positive predictive value (PPV) and negative predictive value (NPV) of $75 \%$ and $81 \%$, respectively at $\mathrm{HbA} 1 \mathrm{c}$ cutoff value of $>5.7 \%{ }^{36}$ They reported that the concordance between OGTT and HbA1c is poor in diagnosis of normal glucose tolerance, diabetes and pre-diabetes and hence did not favour use of $\mathrm{HbA} 1 \mathrm{c}$ in predicting GDM.

Hughes et al used HbA1c value of $5.9 \%$ as cut-off and got a $100 \%$ sensitivity and $97.4 \%$ specificity. ${ }^{37}$ The positive predictive value was $18.8 \%$ and NPV of $100 \%$. They concluded that with $\mathrm{HbA} 1 \mathrm{c} \geq 5.9 \%$, it is possible to identify all the women with GDM who are high risk for adverse outcomes in pregnancy hence affirming the efficacy of HbA1c in predicting GDM.

Odsaeter et al, in their study on 677 women belonging to Nordic Caucasian ethinic background, studied efficacy of $\mathrm{HbA} 1 \mathrm{c}$ at different values and found that at cut-off values of $<4.7 \%,>5.4 \%$ and $5.6 \%$, the sensitivities are $100 \%$, $14.6 \%$ and $7.3 \%$, respectively. ${ }^{38}$ The corresponding specificity values for these cut-offs were $0.6 \%, 93.6 \%$ and $100 \%$, respectively. They concluded that $\mathrm{HbA} 1 \mathrm{c}$ could potentially reduce the numbers of OGTT.

Rajput et al conducted a study in Rohtak, India and reported that with cut-off value of $>5.45 \%$, HbA1c has a $85.7 \%$ sensitivity and $61.1 \%$ specificity in predicting GDM. ${ }^{39}$ These figures became $28.6 \%$ and $97.2 \%$, respectively with $\mathrm{HbA} 1 \mathrm{c}$ cut-off of $>5.95 \%$. They further concluded that the OGTT could be eliminated in $61.8 \%$ patients by using $\mathrm{HbA} 1 \mathrm{c}$.

Renz et al, in their prospective study conducted in Brazil, studied HbA1c by evaluating its efficacy at different values. $^{40}$ They found that with $5.8 \%$ of cut-off, the sensitivity and specificity was $26.4 \%$ and $94.9 \%$. But, they concluded that in spite of the low sensitivity, HbA1c could be an effective tool for screening GDM which can help to avoid the inconvenient OGTT in almost a third of the patients, and that further studies need to be done for confirmation.

On the other hand, Ryu et al, after studying the sensitivities and specificities of HbA1c at various cut-off values, found that at $5.35 \%, \mathrm{HbA} 1 \mathrm{c}$ has sensitivity, specificity, PPV and NPV of $87.2 \%, 70.9 \%, 58.3 \%$ and $92.2 \%$, respectively. ${ }^{41}$ In spite of these significant values it was concluded in the study that HbA1c cannot replace the current standard OGTT for diagnosis of GDM.

Soumya et al in their study found that the HbA1c at a value of $5.3 \%$, has sensitivity of $95.6 \%$, specificity if $51.6 \%$, PPV of $16 \%$ and NPV of $99 \% .^{42}$ These figures are $73.7 \%$,
$75 \%, 21.5 \%$ and $96.7 \%$ with the cut-off of $5.7 \%$. In this study they performed $\mathrm{HbA} 1 \mathrm{c}$ at gestational age of 24-28 weeks and they found that $\mathrm{HbA} 1 \mathrm{c}$ cannot replace the OGTT but can be an effective screening tool which can avoid OGGT in almost half the antenatal women with a cut-off value of $5.3 \%$.

Sujithra et al, on the other hand obtained a specificity of $93.2 \%$, sensitivity of $70.4 \%$, PPV and NPV of $79.2 \%$ and $89.5 \%$, respectively using $5.7 \%$ value of $\mathrm{HbA} 1 \mathrm{c}$ and reported the usefulness of $\mathrm{HbA} 1 \mathrm{c}$ as an efficacious tool for prediction of GDM. ${ }^{43}$

Ye et al took a HbA1c cut-off value of $5.5 \%$ to obtain a specificity of $95.7 \%$ and sensitivity of $14.8 \%$. They concluded that even with low sensitivity, HbA1c could be useful in screening GDM but further studies need to be done to confirm the same. ${ }^{44}$

An overlook at these studies suggests that maximum efficacy of $\mathrm{HbA} 1 \mathrm{c}$ in diagnosing GDM is seen at values in the range of $5.4-5.9 \%$.

\section{CONCLUSION}

After reviewing articles on efficacy of $\mathrm{HbA1c}$ in screening GDM, it can be concluded that HbA1c may used as an effective tool for predicting and screening GDM and can obviate need for OGTT in significant number of antenatal mothers. A convenient and simpler test like HbA1c provides ability to avoid the cumbersome and timeconsuming OGTT in low risk patients with additional benefits of prevention of fetal and maternal morbidities if tested early. The studies around world suggest the need for pregnancy-specific cut-off values of HbA1c. These studies show that this cut-off could lie in a range of 5.4-5.9\% and further studies should be undertaken to obtain a more specific value. With the evolving utility of HbAlc in current scenarios, this study emphasizes on the need for more studies to assess the value of HbA1c in GDM screening especially in the early gestation.

Funding: No funding sources Conflict of interest: None declared

Ethical approval: Not required

\section{REFERENCES}

1. Mahalakshmi MM, Bhavadharini B, Maheswari Kumar RM, Shah SS, Bridgette A, Choudhury M, et al. Clinical profile, outcomes, and progression to type 2 diabetes among Indian women with gestational diabetes mellitus seen at a diabetes center in south India. Indian J Endocrinol Metab. 2014;18(3):400-6.

2. Yogev Y, Visser GH. Obesity, gestational diabetes and pregnancy outcome. Semin Fetal Neonatal Med. 2009;14(2):77-84.

3. Anjana RM, Pradeepa R, Deepa M, Datta M, Sudha V, Unnikrishnan R, et al. Prevalence of diabetes and prediabetes (impaired fasting glucose and/or impaired 
glucose tolerance) in urban and rural India: Phase I results of the Indian Council of Medical ResearchINdiaDIABetes (ICMR-INDIAB) study. Diabetologia. 2011;54(12):3022-7.

4. Mithal A, Bansal B, Kalra S. Gestational diabetes in India: Science and society. Indian $\mathrm{J}$ Endocrinol Metab. 2015;19(6):701-4.

5. Abate N, Chandalia M. Ethnicity, type 2 diabetes \& migrant Asian Indians. Indian J Med Res. 2007;125(3):251-8.

6. Casey BM, Lucas MJ, McIntire DD, Leveno KJ. Pregnancy outcomes in women with gestational diabetes compared with the general obstetric population. Obstet Gynecol. 1997;90(6):869-73.

7. Dang K, Homko C, Reece EA. Factors associated with fetal macrosomia in offspring of gestational diabetic women. J Matern Fetal Med. 2000;9(2):114-7.

8. Hillier TA, Pedula KL, Schmidt MM, Mullen JA, Charles MA, Pettitt DJ. Childhood obesity and metabolic imprinting: the ongoing effects of maternal hyperglycemia. Diabetes care. 2007;30(9):2287-92.

9. Naylor CD, Sermer M, Chen E, Sykora K. Cesarean delivery in relation to birth eight and gestational glucose tolerance: pathophysiology or practice style? JAMA. 1996;275(15):1165-70.

10. Yogev Y, Ben-Haroush A, Chen R, Glickman H, Kaplan B, Hod M. Active induction management of labor for diabetic pregnancies at term; mode of delivery and fetal outcome-a single center experience. Eur J Obstet Gynecol Reprod Biol. 2004;114(2):16670 .

11. Balaji V, Madhuri BS, Ashalatha S, Sheela S, Suresh $\mathrm{S}$, Seshiah V. A1C in gestational diabetes mellitus in Asian Indian women. Diabetes care. 2007;30(7):1865-7.

12. Balaji V, Balaji MS, Seshiah V, Mukundan S, Datta M. Maternal glycemia and neonates birth weight in Asian Indian women. Diabetes Res Clin Pract. 2006;73(2):223-4.

13. Amreen S, Suneel A, Shetty A, Vasudeva A, Kumar P. Use of glycosylated HbA1c and random blood sugar as a screening tool for gestational diabetes mellitus in first trimester. Int J Reprod Contracept Obstet Gynecol. 2018;7(2):524-8.

14. Cefalu WT, Berg EG, Saraco M, Petersen MP, Uelmen S, Robinson S. Classification and diagnosis of diabetes: standards of medical care in diabetes2019. Diabetes Care. 2019;42:S13-28.

15. Karakash SD, Einstein FH. Diabetes in pregnancy: glycemia control guidelines and rationale. Curr Opin Endocrinol Diabetes Obes. 2011;18(2):99-103.

16. Angueira AR, Ludvik AE, Reddy TE, Wicksteed B, Lowe WL, Layden BT. New insights into gestational glucose metabolism: lessons learned from 21st century approaches. Diabetes. 2015;64(2):327-34.

17. Di Cianni G, Miccoli RO, Volpe LA, Lencioni C, Del Prato ST. Intermediate metabolism in normal pregnancy and in gestational diabetes. Diabetes Metab Res Rev. 2003;19(4):259-70.
18. Butte NF. Carbohydrate and lipid metabolism in pregnancy: normal compared with gestational diabetes mellitus. Am J Clin Nutr. 2000;71(5):1256S$61 \mathrm{~S}$.

19. Newbern D, Freemark M. Placental hormones and the control of maternal metabolism and fetal growth. Curr Opin Endocrinol Diabetes Obes. 2011;18(6):409-16.

20. Plows JF, Stanley JL, Baker PN, Reynolds CM, Vickers MH. The pathophysiology of gestational diabetes mellitus. Int J Mol Sci. 2018;19(11):3342.

21. Patti ME, Corvera S. The role of mitochondria in the pathogenesis of type 2 diabetes. Endocrine Reviews. 2010;31(3):364-95.

22. Homko C, Sivan E, Chen X, Reece EA, Boden G. Insulin secretion during and after pregnancy in patients with gestational diabetes mellitus. J Clin Endocrinol Metab. 2001;86(2):568-73.

23. Catalano PM, Tyzbir ED, Roman NM, Amini SB, Sims EA. Longitudinal changes in insulin release and insulin resistance in nonobese pregnant women. Am J Obstet Gynecol. 1991;165(6):1667-72.

24. Cheung NW, Wasmer G, Al-Ali J. Risk factors for gestational diabetes among Asian women. Diabetes Care. 2001;24(5):955-6.

25. Lee KW, Ching SM, Ramachandran V, Yee A, Hoo FK, Chia YC, et al. Prevalence and risk factors of gestational diabetes mellitus in Asia: a systematic review and meta-analysis. BMC Pregnancy Childbirth. 2018;18(1):494.

26. Cunningham FG, Leveno KJ, Bloom SL, Dashe JS, Hoffman BL, Casey BM, Spong CY (editors). Williams Obstetrics. 25thed. New York: McGrawHill Education; 2018;7:2444-8.

27. Cunningham FG, Leveno KJ, Bloom SL, Dashe JS, Hoffman BL, Casey BM, Spong CY (editors). Williams Obstetrics. 25thed. New York: McGrawHill Education; 2018;57:2437-42.

28. Cunningham FG, Leveno KJ, Bloom SL, Dashe JS, Hoffman BL, Casey BM, Spong CY (editors). Williams Obstetrics. 25thed. New York: McGrawHill Education; 2018;57:2442-4.

29. Metzger BE, Gabbe SG, Persson B, Buchanan TA, Catalano PA, Damm P, et al. International association of diabetes and pregnancy study groups recommendations on the diagnosis and classification of hyperglycemia in pregnancy. Diabetes Care. 2010;33(3):676-82.

30. Fuller KP, Borgida AF. Gestational diabetes mellitus screening using the one-step versus two-step method in a high-risk practice. Clin Diabetes. 2014;32(4):14850.

31. Kobold U, Jeppsson JO, Dulffer T, Finke A, Hoelzel W, Miedema K. Candidate reference methods for hemoglobin A1c based on peptide mapping. Clin Chem. 1997;43(10):1944-51.

32. Kaveeshwar SA, Cornwall J. The current state of diabetes mellitus in India. Australas Med J. 2014;7(1):45-8.

33. Agarwal MM, Dhatt GS, Punnose J, Koster G. Gestational diabetes: a reappraisal of HBA1c as a 
screening test. Acta Obstet Gynecol Scand. 2005;84(12):1159-63.

34. Aldasouqi SA, Solomon DJ, Bokhari SA, Khan PM, Muneera S, Gossain VV. GlycohemoglobinA1c: a promising screening tool in gestational diabetes mellitus. Int J Diabetes Dev Ctries. 2008;28(4):121-4.

35. Arbib N, Shmueli A, Salman L, Krispin E, Toledano Y, Hadar E. First trimester glycosylated hemoglobin as a predictor of gestational diabetes mellitus. Int $\mathrm{J}$ Gynaecol Obstet. 2019;145(2):158-63.

36. Duke A, Yap C, Bradbury R, Hng TM, Kim C, Wansbrough A, et al. The discordance between HbA1c and glucose tolerance testing for the postpartum exclusion of diabetes following gestational diabetes. Diabetes Res Clin Pract. 2015;108(1):72-7.

37. Hughes RC, Moore MP, Gullam JE, Mohamed K, Rowan J. An early pregnancy $\mathrm{HbAlc} \geq 5.9 \%$ (41 $\mathrm{mmol} / \mathrm{mol}$ ) is optimal for detecting diabetes and identifies women at increased risk of adverse pregnancy outcomes. Diabetes Care. 2014;37(11):2953-9.

38. Odsæter IH, Åsberg A, Vanky E, Mørkved S, Stafne SN, Salvesen KA, Carlsen SM. Hemoglobin A1c as screening for gestational diabetes mellitus in Nordic Caucasian women. Diabetol Metab Syndr. 2016;8(1):43.

39. Rajput R, Rajput M, Nanda S. Utility of HbA1c for diagnosis of gestational diabetes mellitus. Diabetes Res Clin Pract. 2012;98(1):104-7.
40. Renz PB, Cavagnolli G, Weinert LS, Silveiro SP, Camargo JL. HbA1c test as a tool in the diagnosis of gestational diabetes mellitus. PLoS One. 2015;10(8):e0135989.

41. Ryu AJ, Moon HJ, Na JO, Kim YJ, Kim SJ, Mo SI, et al. The usefulness of the glycosylated hemoglobin level for the diagnosis of gestational diabetes mellitus in the Korean population. Diabetes Metab J. 2015;39(6):507-11.

42. Soumya S, Rohilla M, Chopra S, Dutta S, Bhansali A, Parthan G, et al. HbA1c: a useful screening test for gestational diabetes mellitus. Diabetes Technol Ther. 2015;17(12):899-904.

43. Sujithra D., Mukherjee S, Sudha S. Glycated hemoglobin in early pregnancy as a predictor of gestational diabetes mellitus. Ind J Obstet Gynecol Res. 2018;5(3):327-30.

44. Ye M, Liu Y, Cao X, Yao F, Liu B, Li Y, et al. The utility of HbA1c for screening gestational diabetes mellitus and its relationship with adverse pregnancy outcomes. Diabetes Res Clin Pract. 2016;114:43-9.

Cite this article as: Shendre SD, Palanisamy V, Rewatkar SS. Glycosylated hemoglobin as an efficacious tool for early prediction of gestational diabetes mellitus. Int J Reprod Contracept Obstet Gynecol 2021;10:1747-52. 